\title{
Assessing shade stress in leaves of turf-type tall fescue (Festuca arundinacea Schreb.)
}

\author{
Q. $\mathrm{HE}^{*}$ and D. $\mathrm{LI}^{* *,+}$ \\ College of Forestry and Landscape Architecture, South China Agricultural University, 510642 Guangzhou, China* \\ Department of Plant Sciences, North Dakota State University, Fargo, ND 58108, USA**
}

\begin{abstract}
Shade treatment was applied to tall fescue with $30 \%$ full light. The results showed that shade increased chlorophyll (Chl) content per unit leaf mass, decreased the $\mathrm{Chl} a / b$ ratio in the mature leaves, and decreased effective quantum yield based on Chl fluorescence compared to the full light treatment. Shade stress did not cause increased contents of malondiadehyde at the early stages of leaf development. However, normalized vegetation indices were able to detect shade stress. Chloroplasts in the shaded leaves are arranged tightly against the periclinal cell wall and are in a spindle shape. There were no differences in the number of grana per chloroplast or grana size (thylakoids per granum) between shade and full light treatment. In conclusion, tall fescue leaves showed unique ultrastructure changes. Turfgrass managers could use vegetation indices developed from the leaf light reflection spectrum as an effective tool to assess shade stress levels and make management decisions.
\end{abstract}

Keywords: lawn; low light; photosynthesis; senescence; vegetation index.

\section{Introduction}

Low light intensities negatively affect the growth and stress tolerance of turfgrass (Beard 1997). Shade effects on turfgrass are inevitable around trees and buildings, or in stadiums where natural turfgrasses are used for highquality playing surfaces (Bell et al. 2000, Matsubara et al. 2019). There is a large variation in the levels of shade tolerance among turfgrass species and cultivars (Gilbert and DiPaola 1985, Van Huylenbroeck and Van Bockstaele 2001). $C_{3}$ cool-season grasses are generally more tolerant to shade than $\mathrm{C}_{4}$ warm-season grasses (Kephart and Buxton 1993, Awada et al. 2003, Kubásek et al. 2013). Plants growing under a low light intensity suffer from lower net photosynthetic assimilation (Beard 1997). As a result, leaf appearance deteriorates and the total leaf number decreases. Shade may also accelerate leaf senescence (Causin et al. 2006), which shortens the functional period of leaves and decreases carbohydrate reserves in the plant. The decrease in energy accumulation leads to lower tiller density and lower total biomass (Allard et al. 1991a). More importantly, the root system decreases faster than the shoot system, resulting in decreasing the root-to-shoot ratio, and decreases the capacity of water and nutrients uptake (Allard et al. 1991a). Ultimately, extended periods of shade conditions cause poor turfgrass quality and slow

\section{Highlights}

- Shade stress in tall fescue could be assessed using normalized vegetation indices

- Malondiadehyde, an indicator of oxidation, did not increase under shade stress

- Chloroplast arrangement, not ultrastructure, responded to shade in tall fescue
Received 5 April 2021

Accepted 7 July 2021

Published online 28 July 2021

${ }^{+}$Corresponding author

e-mail: deying.li@ndsu.edu

Abbreviations: $\mathrm{Chl}$ - chlorophyll; MDA - malondiadehyde; $\mathrm{mND} 705-\mathrm{mND}_{750 / 705}=\left(\mathrm{R}_{750}-\mathrm{R}_{705}\right) /\left(\mathrm{R}_{750}+\mathrm{R}_{705}-2 \mathrm{R}_{445}\right)$, where $\mathrm{R}$ values are standardized reflection and subscripts indicate reflection wavelength $[\mathrm{nm}] ; \mathrm{mSR} 705-\mathrm{mSR}_{750 / 705}=\left(\mathrm{R}_{750}-\mathrm{R}_{445}\right) /\left(\mathrm{R}_{705}+\mathrm{R}_{445}\right)$, where $\mathrm{R}$ values are standardized reflection and subscripts indicate reflection wavelength [nm]; NDVI - normalized vegetation index; SI - stress index, $\mathrm{SI}_{710 / 760}=\mathrm{R}_{710} / \mathrm{R}_{760}$, where $\mathrm{R}$ values are standardized reflection and subscripts indicate reflection wavelength [nm]; WAT - weeks after treatment.

Conflict of interest: The authors declare that they have no conflict of interest. 
recovery from the damages by traffics and wear (Van Huylenbroeck and Van Bockstaele 2001).

Managing turfgrass under shade requires multiple approaches. Adding artificial lights or periodically providing natural sunlight by opening the roof or transporting turfgrass modules outdoors is cost-prohibitive and applies only to a few high-profile facilities (Hunter et al. 2009). Photosynthetic rates are affected by many environmental factors, such as temperature, nutrients, and $\mathrm{CO}_{2}$ concentration as well as light quality and quantity (Allard et al. 1991b, Roeber et al. 2021). Optimizing all conditions in addition to using shade-tolerant species/cultivars adds to the chances of success (Schwartz et al. 2020). Therefore, it is important to understand turfgrass growth and physiological reactions to shade, accurately assess the health status, and use effective management practices for turfgrass under shade.

Plants have different mechanisms to adapt to the conditions of low light intensity. Some species express a lower light-compensation point (Van Huylenbroeck et al. 1999), increased leaf area index (Cayssials and Rodríguez 2013), larger specific leaf area (Woledge 1971, Allard et al. 1991a), and produce thinner leaves (Pandey and Kushwaha 2005). Other mechanisms include increasing Chl content (Murchie and Horton 1997), decreasing stomatal conductance and dark respiration rate (Woledge 1971, Allard et al. 1991b). The amounts of Chl $a$ are usually higher than that of Chl $b$ when the leaves are under moderate or low light intensity compared to under high light before leaf senescence (Behera and Choudhury 2001). The maximal quantum yield of PSII photochemistry in the dark-adapted leaves $\left(\mathrm{F}_{\mathrm{v}} / \mathrm{F}_{\mathrm{m}}\right)$ was not affected by the light intensity in sunflower (Helianthus annuus L.) (Yamazaki and Shinomiya 2013). Plants may also be capable of adjusting leaf position architecture and leaf structure (Boardman 1977, Prioul et al. 1980, Cayssials and Rodríguez 2013) for higher light absorption efficiency in response to low light intensity. At the subcellular level, shade-type chloroplasts show higher amounts of thylakoid stacks and fewer grana per chloroplast (Gregoriou et al. 2007, Mathur et al. 2018). At the whole-plant level, development and growth show different degrees of plasticity by regulating carbohydrate allocation under shade (Guenni et al. 2018). Plant breeders can more effectively include important traits for shade tolerance by understanding the shade-tolerant mechanisms and by using accurate and affordable assessment methods.

Tall fescue has a relatively strong shade tolerance among commonly used cool-season turfgrasses (Gilbert and DiPaola 1985, Van Huylenbroeck et al. 1999, Gardner and Taylor 2002). It is also a species with excellent tolerance to heat, drought, and salinity (Gao and Li 2012). The specific leaf area of tall fescue increased under shade resulting in an increased photosynthetic rate based on unit leaf dry mass, while the dark respiration rates decreased under shade based on either leaf area or dry mass (Woledge 1971). There is a lack of information on other physiological parameters in turf-type tall fescue under shade stress. Parameters, such as Chl fluorescence, Chl content, leaf water potential, which reveal different aspects of photosynthetic activity, may be treated as different traits in the breeding process (Estrada et al. 2015). However, under shade conditions, some $\mathrm{Chl}$ fluorescence parameters may not show any differences from those under full light (Jiang et al. 2005). On the other hand, turfgrass quality was shown to be correlated to normalized vegetation index (NDVI) under shade conditions (Chhetri et al. 2019). The primary objective of this experiment was to identify some physiological parameters to assess shade stress and to understand the effects of shade on the chloroplast structure in leaves of turf-type tall fescue. We used two varieties with different drought tolerance (Gao and Li 2012) because of the lack of information regarding shade tolerance about commercially used varieties. Nevertheless, research results indicate that plant response to light intensity may be associated with sensitivities to drought stress (Petrova et al. 2020).

\section{Materials and methods}

Plant materials and culture conditions: The experiment was conducted in a greenhouse maintained at $25 / 15^{\circ} \mathrm{C}$ (day/night), $14 \mathrm{~h} / 10 \mathrm{~h}$ (light/dark) photoperiod, and an average PAR of $400 \mu \mathrm{mol}$ (photon) $\mathrm{m}^{-2} \mathrm{~s}^{-1}$ supplemented with metal halide lamps. Turfgrass varieties, Tar Heel II and Wolfpack, were selected in this experiment. The seeds were planted in plastic tubes $(4 \mathrm{~cm}$ in diameter and $20 \mathrm{~cm}$ in depth) with silicon sand as the growth medium. The growth medium was maintained at field capacity by watering twice daily until the seeds germinated, then the watering frequency was reduced to once daily. The seedlings were fertilized with half-strength Hoagland solution (Hothem et al. 2003) at $10 \mathrm{ml}$ per tube twice a week. The plants were thinned to one plant per tube at the two-leaf stage.

Shade treatment: At the four-leaf stage, we applied fullstrength Hoagland solution to the sand medium at $20 \mathrm{ml}$ per tube every other day and initiated the shade treatment. The shade was provided by placing a black polyethylene net over plants, which allows $30 \%$ full light to pass through. This was confirmed by measurement using a quantum sensor (LI-190R, LI-COR Biosciences, Nebraska, USA) and a pyranometer (LI-200R, LI-COR Biosciences, Nebraska, USA). The plants without shade cover were the control treatment. Within a replicate, each shade level of a tall fescue variety included 98 plants. The experiment was arranged in a randomized complete block design with three replicates and was conducted twice.

Quantum yield and light reflection spectrum: Weekly measurements were taken from the fourth leaf after the initiation of shade treatment and from other younger leaves on the primary shoot five weeks after the treatment. The effective quantum yield of photochemical energy conversion was measured under actinic light from three plants in each experiment unit using a portable $\mathrm{Chl}$ fluorometer MINI-PAM (Heinz Walz GmbH, Effeltrich, Germany) with the fiberoptics placed $6 \mathrm{~mm}$ to the leaf surface at $60^{\circ}$ angle. The white actinic light had an intensity of PAR of $400 \mu \mathrm{mol}$ (photon) $\mathrm{m}^{-2} \mathrm{~s}^{-1}$ measured 
using the quantum sensor. The same leaves were used to collect reflectance spectrum within the wavelengths of 350-1,000 nm using an $S 2000-T R$ temperature-regulated fiber-optic spectrometer (OceanOptics Inc., Dunelin, FL) with a fiber-optic cable at $60^{\circ}$ to the leaf surface. The leaf was clipped on a black background with the adaxial side facing up in a dark chamber. The leaf chamber was illuminated by a high-intensity halogen light (WarnerLambert Tech. Inc., Buffalo, NY) from the top before the spectrum collection. Three reflectance indices, $\mathrm{mSR}_{750 / 705}$

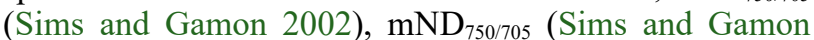
2002), and $\mathrm{SI}_{710 / 760}$ (Carter 1994), were calculated from the relative reflective spectra using the following equations: $\mathrm{mSR}_{750 / 705}=\left(\mathrm{R}_{750}-\mathrm{R}_{445}\right) /\left(\mathrm{R}_{705}+\mathrm{R}_{445}\right), \mathrm{mND}_{750 / 705}=$ $\left(\mathrm{R}_{750}-\mathrm{R}_{705}\right) /\left(\mathrm{R}_{750}+\mathrm{R}_{705}-2 \mathrm{R}_{445}\right), \mathrm{SI}_{710 / 760}=\mathrm{R}_{710} / \mathrm{R}_{760}$, where $\mathrm{R}$ is the relative reflectance at a given wavelength. The justification for using these three indices was based on a previous assessment of salinity tress in tall fescue (Gao and Li 2012).

Chl and MDA: After the collection of reflectance spectrum, the fourth leaves from six plants were cut off from the plant, flash-frozen in liquid nitrogen, and kept under $-80^{\circ} \mathrm{C}$ for the measurements of $\mathrm{Chl}$ and malondialdehyde (MDA) content. Approximately $0.03 \mathrm{~g}$ of each leaf sample was ground, weighed, and placed in a centrifuge tube for Chl measurement. To each sample, $2 \mathrm{~mL}$ of $80 \%$ acetone was added. The tubes then were capped and kept in darkness overnight at $4{ }^{\circ} \mathrm{C}$ before centrifugation. Each $50 \mu \mathrm{L}$ of the supernatant was diluted by adding $950 \mu \mathrm{L}$ of $80 \%$ acetone before the measurement of light absorbance using a Beckman DU 640 spectrophotometer (Beckman Instruments Inc., Fullerton, CA) at the wavelengths of $470,646.8$, and $663.2 \mathrm{~nm}$. The $\mathrm{Chl}$ content was determined following the method by Lichtenthaler (1987).

Malondialdehyde content was determined by the thiobarbturic acid (TBA) reaction following the method of Heath and Packer (1968) and the correction of nonspecific absorbance at $532 \mathrm{~nm}$ proposed by Hodges et al. (1999). The leaf samples were ground, extracted with $1.0 \mathrm{ml}$ of $5 \%$ trichloroacetic acid, and centrifuged immediately. Equal volumes of $0.5 \mathrm{ml}$ of supernatant and $0.67 \%$ TBA were mixed in a new centrifuge tube. The mixture was incubated in a water bath at $100^{\circ} \mathrm{C}$ for $30 \mathrm{~min}$. The light absorbance of the mixtures was measured at the wavelengths of 450, 532, and $600 \mathrm{~nm}$ using a Beckman DU 640 spectrophotometer.

Ultrastructure of chloroplast: The fourth leaves on the primary shoot were collected one week after shade treatment for transmission electron microscopy. The specimens were immediately fixed in $2.5 \%$ glutaraldehyde in $0.1 \mathrm{M}$ sodium phosphate buffer, $\mathrm{pH} 7.35$ (Tousimis Research Corporation, Rockville, MD) and stored in a refrigerator at $4^{\circ} \mathrm{C}$ for at least two hours. Thereafter, they were rinsed with the buffer and placed in the buffer containing $2 \%$ osmium tetroxide for two hours at room temperature. Following a series of dehydration in a graded acetone, samples were embedded in Epon-Araldite-DDSA with a $D M P-30$ accelerator and sliced into sections of $60-\mathrm{nm}$ thickness on RMC MTXL ultramicrotome (Boeckeler
Instruments, Tucson, AZ). The sections were stained with lead citrate on specimen grids for $2.5 \mathrm{~min}$ and dried before observation under a JEOL JEM-100CX II electron microscope (JEOL Inc., Peabody, MA). The number of grana per chloroplast was counted in each field of view under the electron microscope at 29,300× magnification. The number of thylakoids was counted in each field of view under the electron microscope at 58,700× magnification.

Statistical analysis: The data were subjected to analysis of variance ( $A N O V A)$ using a mixed model in the mixed procedures in SAS 9.4 (SAS Institute, 2013) with the runs and the replicates within runs treated as random variables. The two runs were combined after testing the homogeneity of variance using the $F$-test. The measurements at different weeks after treatment (WAT) were included in the model as repeated measurements. Treatment means were separated using Tukey's significant difference (HSD) at the 0.05 probability level.

\section{Results and discussion}

Statistical analysis: The variances from the two runs of the experiment were homogeneous based on the $F$-test of the ratios of the error terms of the two runs (both had six degrees of freedom). The ANOVA of the combined two runs showed no differences between the two varieties of tall fescue for all the measurements and no interactions between variety and shade treatment (Tables 1S, 2S; supplement). The time effect, as well as shade and time interaction parameters, were also significant indicating that plant response to shade stress was dependent on leaf age. Therefore, the results were presented focusing on the shade effects by pooling the two varieties.

Effective quantum yield and Chl: Shade reduced the effective quantum yield of PSII as compared to fulllight control (Fig. 1, Table 1S). This is different from the results found for maximum quantum yield in sunflower (Yamazaki and Shinomiya 2013). The fact that maximum quantum yield did not differentiate shade stress from full light was also reported in turfgrass (Jiang et al. 2005). However, the effective quantum yield was different between leaves under different light intensities (Sagun et al. 2019).

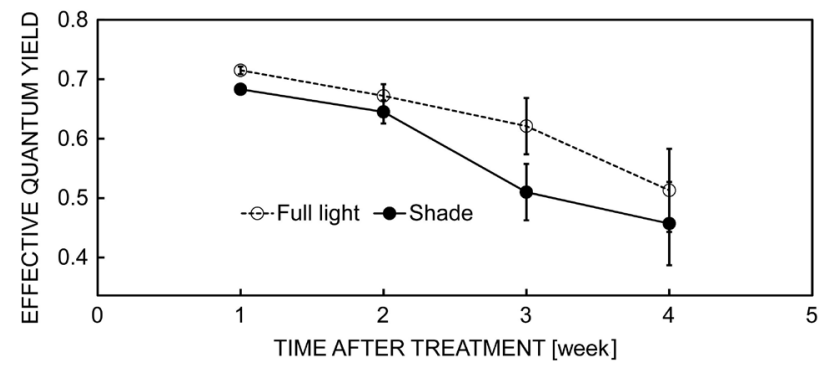

Fig. 1. Effective quantum yield of photosystem II of the fourth mature leaf on the primary tiller of two turf-type tall fescue varieties, Tar Heel II and Wolfpack. Means were presented with $\pm 1 \mathrm{SE}(n=12)$. 
There have been reports that maximum quantum yield of PSII differ for leaves under different shade (Lichtenthaler et al. 2013). Therefore using leaf fluorescence parameters to detect shade stress is species-dependent. The Chl content on the dry-mass basis in the fourth leaf was higher in the shade treatment than that in the full-light treatment with the content decreasing in time for both treatments (Fig. 2). The Chl $a / b$ ratio was lower in shaded leaves than those exposed to full light (Fig. 2). The changes in Chl content and ratio under shade were in agreement with earlier reports on tall fescue (Woledge 1971). Despite the increasing photosynthetic rate with increasing Chl content reported earlier (Woledge 1971), we found that the overall quantum efficiency of the mature leaves of tall fescue decreased under shade. This indicated other factors in addition to Chl content, such as chloroplast structure, may be responsible. The content of Chl decreased over time regardless of shade or full-light conditions indicating that shade effects were similar at different stages of leaf growth. The ratio of $\mathrm{Chl} a / b$ was stable for the first three weeks but decreased significantly in the fourth week of measurement (Fig. 2). At the fourth week of measurement, the difference in the ratio of $\mathrm{Chl} a / b$ between shade and full light treatment diminished, indicating that senescence was the major cause of the changes at this stage.

Normalized vegetation indices: The vegetation indices developed from the fourth leaf spectrum also showed differences between the shaded and full-light treatments at all measurement dates (Table 1S). Both mSR705 and mND705 were lower in shaded leaf than the one exposed to full light (Fig. 3). The results were expected because these two indices are positively correlated to the photosynthetic rate (Gao and Li 2012). On the other hand, SI was higher in the shaded leaves than those in the full light (Fig. 3) because SI as an indicator of stress levels is based on the photon-use efficiency of leaves (Carter 1994, Gao and Li

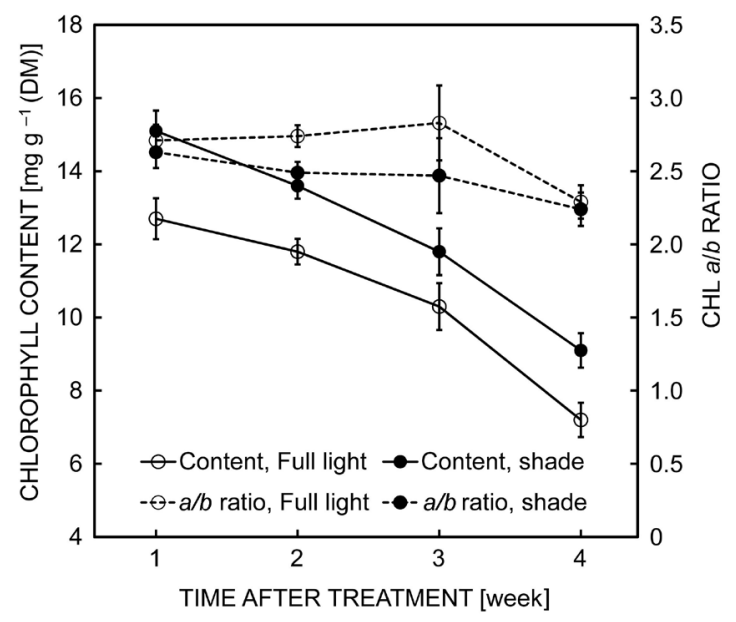

Fig. 2. Chlorophyll (Chl) content and $\mathrm{Chl} a / b$ ratio in the fourth mature leaf on the primary tiller of two turf-type tall fescue varieties, Tar Heel II and Wolfpack. Means were presented with \pm 1 SE $(n=12)$.
2012). There was also a significant interaction between shade treatment and time for the SI, indicating the stress was also reflecting the leaf senescence (Table 1S). The MDA content was higher in leaves exposed to full light than those in the shade (Fig. 4). Malondialdehyde has been used as a lipid peroxidation indicator in oxidative stress and redox signaling (Missihoun et al. 2018). However, MDA content did not increase with the SI values in the shaded leaves in this experiment. This indicated that the oxidation levels of shaded leaves were lower than that of the leaves exposed to full light. Therefore, MDA content may not be an effective indicator of shade stress levels other than a transient signal or an oxidative indicator. This is also supported by the fact that an interaction existed between shade and time for MDA content, indicating leaf senescence also affected MDA.

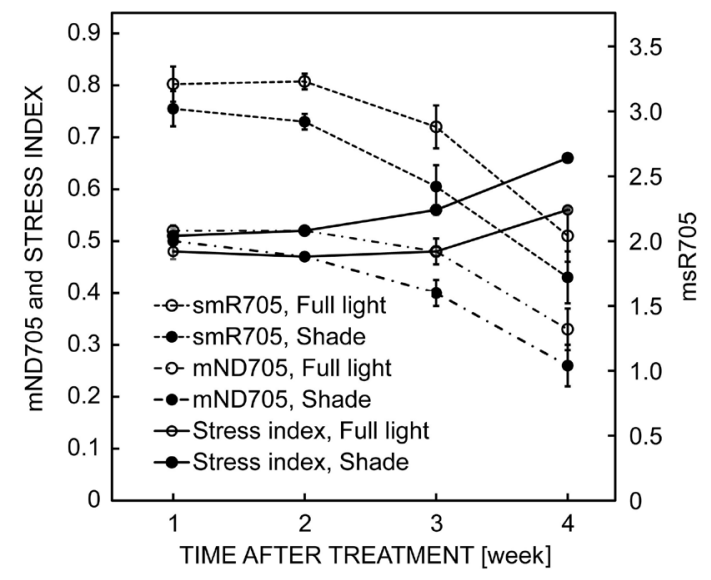

Fig. 3. Normalized vegetation indices from a single leaf spectrum of the fourth mature leaf on the primary tiller of two turf-type tall fescue varieties, Tar Heel II and Wolfpack. Means were presented with $\pm 1 \mathrm{SE}(n=12) . \mathrm{mSR}_{750 / 705}=\left(\mathrm{R}_{750}-\mathrm{R}_{445}\right) /\left(\mathrm{R}_{705}+\mathrm{R}_{445}\right)$, $\mathrm{mND}_{750 / 705}=\left(\mathrm{R}_{750}-\mathrm{R}_{705}\right) /\left(\mathrm{R}_{750}+\mathrm{R}_{705}-2 \mathrm{R}_{445}\right)$, and $\mathrm{SI}_{710 / 760}=$ $\mathrm{R}_{710} / \mathrm{R}_{760}$, where $\mathrm{R}$ is standardized reflection and subscripts indicate reflection wavelength [nm].

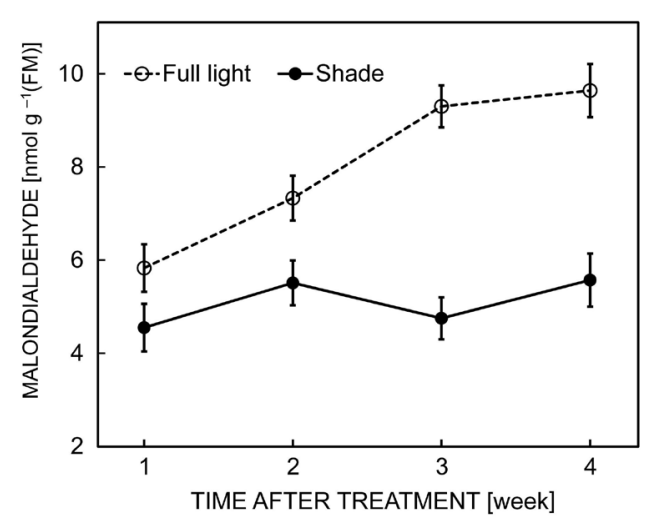

Fig. 4. Malondialdehyde (MDA) content in the fourth mature leaf on the primary tiller of two turf-type tall fescue varieties, Tar Heel II and Wolfpack. Means were presented with \pm 1 SE $(n=12)$. 
Leaf position effects: Five weeks after the initiation of shade treatment, newly appeared leaves also showed decreased effective quantum yield because of the shade treatment (Table 2S). The differences between shade and full-light treatments for these younger leaves were also shown in the vegetation indices (Table 2S). The younger leaf showed a higher reduction in quantum yield than the fourth leaf on the primary shoot (Fig. 5). Similarly, mSR705 and mND705 decreased more in the younger leaves due to shade treatment than the fourth leaf, which had no differences between shaded and full light treatments (Fig. 6). This indicates that the fourth leaf was perhaps entering senescence phase at 5 WAT. However, SI values were different between shaded and full-light treatments for all fourth, fifth, and sixth leaves five weeks after the initiation of shade treatment (Fig. 6). Again, SI might be just an indication of lower light-harvesting efficiency other than oxidation stress, which is more significant in the leaves at the end of senescence (De La Mata et al. 2013).

Chloroplast ultrastructure: Chloroplasts of the shaded leaves were arranged tightly along and against the periclinal cell wall, and were in a spindle shape, while those in the leaves exposed to full light were more spherical and did not circulate against the cell wall (Fig. 7). Anderson et al. (1973) reported that shaded plants in a tropical forest showed a decreased number of grana and more thylakoids per grana as compared to the leaves of species on the top of the canopy. The thylakoid network structure showed no differences between shade and full-light treatment in terms of the number of grana per chloroplast or grana size (thylakoids per granum) in this experiment (Fig. 8). The numbers of grana per chloroplast were $23.9 \pm 3.8$ and $22.8 \pm 3.4$ for full light and shaded treatments (means \pm standard deviation), respectively $(t=0.494, P=0.63)$. The numbers for thylakoids per granum were $15.9 \pm 8.1$ and $16.4 \pm 6.6$ for full light and shaded treatments (means \pm standard deviation), respectively $(t=0.875$, $P=0.40)$. The change of chloroplast ultrastructure was similar to the effect of salicylic acid treatment as reported

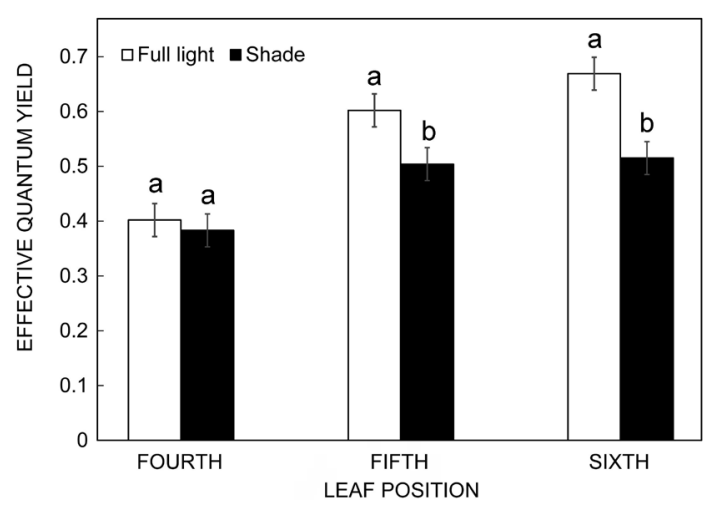

Fig. 5. Effective quantum yield of the fourth, fifth, and sixth mature leaves on the primary tiller of two turf-type tall fescue varieties, Tar Heel II and Wolfpack, five weeks after the shade treatment. Means were separated with $\operatorname{HSD}_{0.05}(n=12)$. by Uzunova and Popova (2000). This suggests that the ultrastructure change is regulated by phytohormones as a response to light fluctuations. This was supported by the findings in light response of Artemisia annua L. (Poulson and Thai 2015) and Solanum lycopersicum L. (Poór et al. 2019). Anderson et al. (2012) reviewed large amounts of publications regarding the thylakoid architecture changes as a mechanism of adaptation to shade in plants. Most of the literature cited was from research conducted on dicotyledonous plants. Zhang et al. (2015) reported that the number of grana per chloroplast and thylakoids per granum showed differences when leaves were exposed to

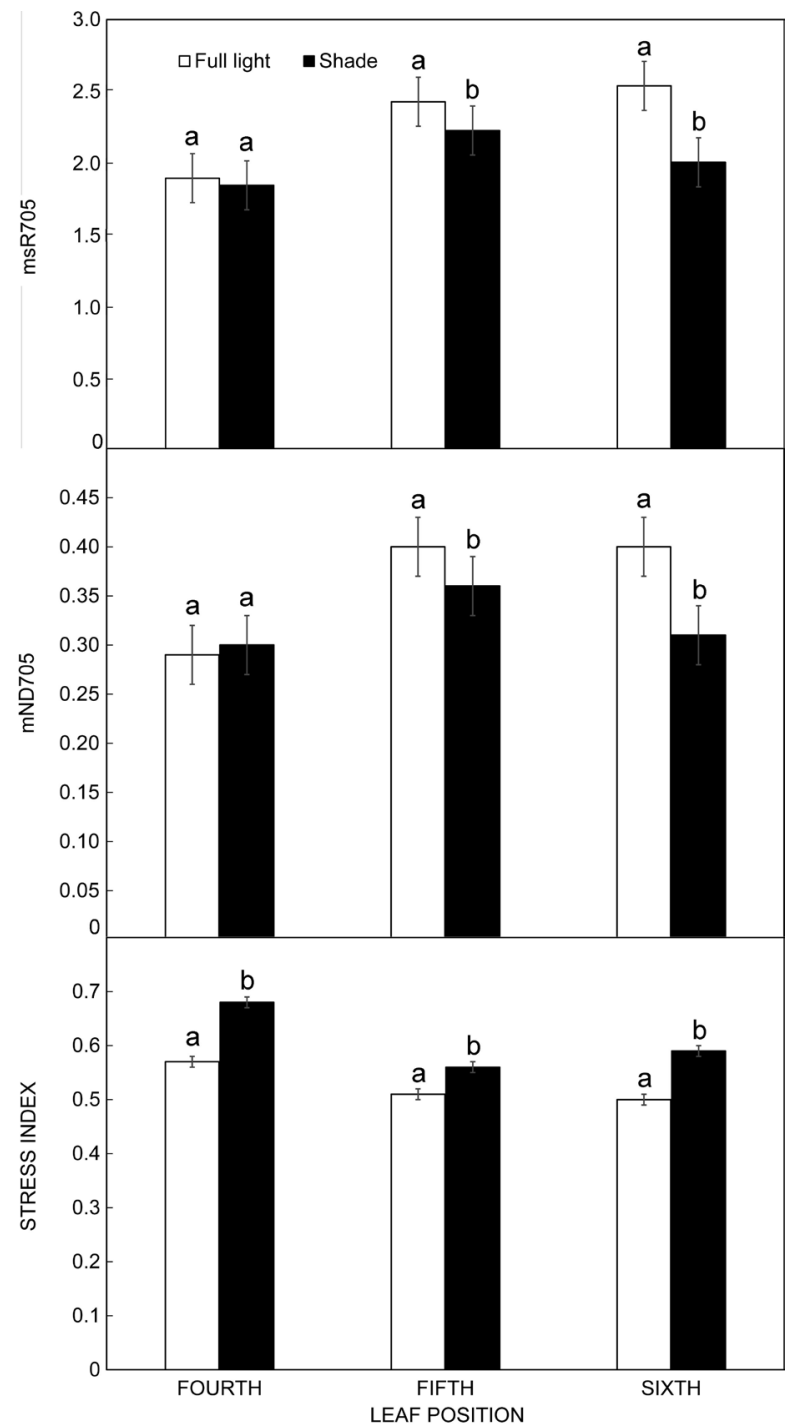

Fig. 6. Normalized vegetation indices from a single leaf spectrum of the fourth, fifth, and sixth mature leaves on the primary tiller of two turf-type tall fescue varieties, Tar Heel II and Wolfpack, five weeks after the shade treatment. Means were separated with $\mathrm{HSD}_{0.05}(n=12) . \mathrm{mSR}_{750 / 705}=\left(\mathrm{R}_{750}-\mathrm{R}_{445}\right) /\left(\mathrm{R}_{705}+\mathrm{R}_{445}\right)$, $\mathrm{mND}_{750 / 705}=\left(\mathrm{R}_{750}-\mathrm{R}_{705}\right) /\left(\mathrm{R}_{750}+\mathrm{R}_{705}-2 \mathrm{R}_{445}\right)$, and $\mathrm{SI}_{710 / 760}=$ $\mathrm{R}_{710} / \mathrm{R}_{760}$, where $\mathrm{R}$ is standardized reflection and subscripts indicate reflection wavelength $[\mathrm{nm}]$. 

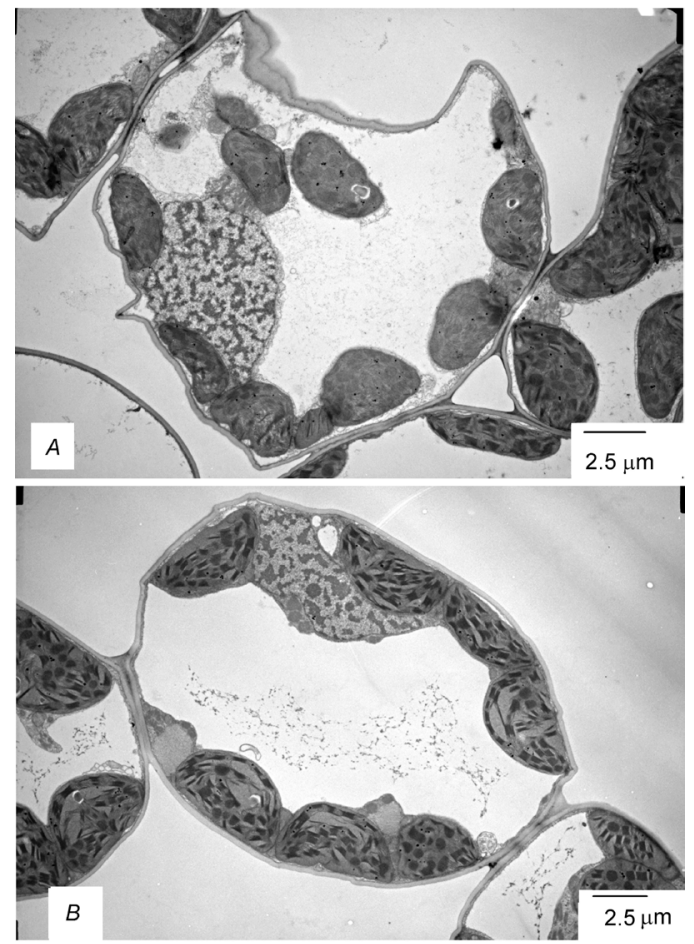

Fig. 7. Transmission electron microscopy of the chloroplast arrangement in mature leaf cells of turf-type tall fescue one week after the shade treatment. $(A)$ full light, $(B)$ shade.

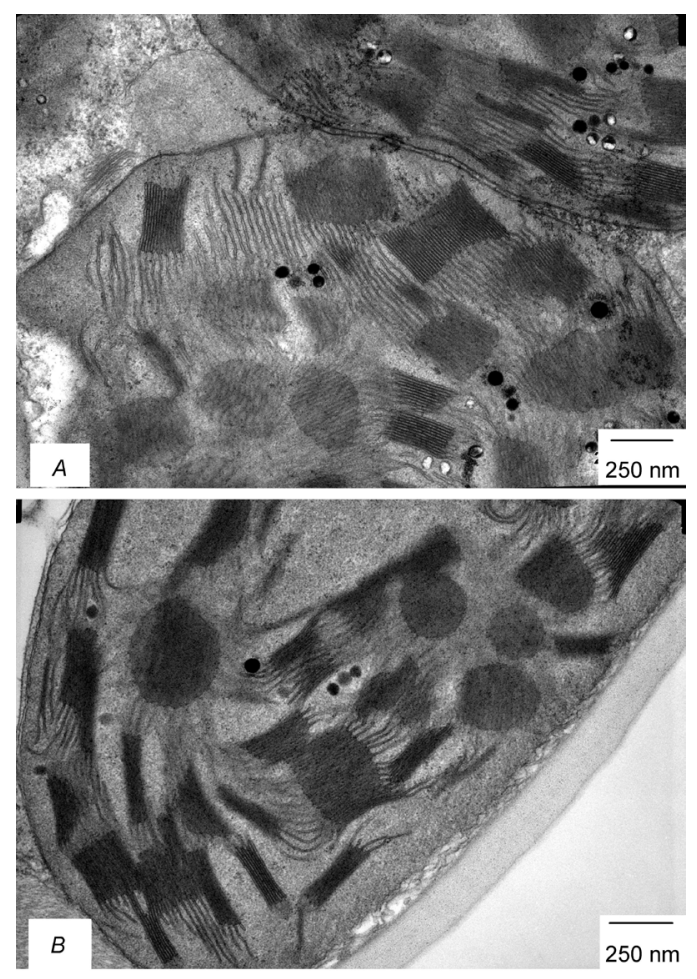

Fig. 8. Transmission electron microscopy of the chloroplast ultrastructure in mature leaf cells of turf-type tall fescue one week after the shade treatment. $(A)$ full light, $(B)$ shade. less than $75 \%$ full light in Glechoma longituba, but a further decrease in light intensity caused no more differences. Kihara et al. (2020) reported the role of chloroplast movement in Oryza species. The relative importance of chloroplast movement and thylakoid structure dynamic in shade tolerance, especially in grasses, remains unknown. We observed a periclinal orientation of grana within the chloroplast in the shade-adapted cells but no significant thylakoid structure changes (Fig. 8). The differences between grass (monocotyledonous) and broadleaf plants may be caused by different morphology, such as stomata, vascular bundle, and bulliform distribution, as well as leaf blade angles to the main stem. Future work should be conducted on grasses to evaluate the chloroplast response in grasses to light intensity fluctuations as well as adaptation to shade environment. Future work should also be done to compare different shade adaptation mechanisms between monocotyledonous and dicotyledonous plants.

Conclusion: Results from this experiment showed that turf-type tall fescue adapted to shade by increasing the total Chl content and decreasing the Chl $a / b$ ratio. Although the photosynthetic rate could be increased with increased Chl content, the effective quantum yield was not maximized. Using normalized vegetation indexes, such as mSR705 and mND705, can effectively assess the leaf performance of tall fescue under shade. Unlike other abiotic stress, shade stress at the early stages of leaf development did not cause increased contents of MDA. On the other hand, using the SI developed from the leaf spectrum revealed shade stress of tall fescue leaves at different developmental stages. The stress levels are also corroborated by decreased effective quantum yield. Our results did not show ultrastructure changes in chloroplasts as reported in dicotyledonous plants. Rather, chloroplast movement caused by shade was observed in turf-type tall fescue as reported in rice. Turfgrass managers could use vegetation indices developed from the leaf light reflection spectrum as an effective tool to assess shade stress levels and make management decisions. More work on the chloroplast structure changes in grasses is needed to understand the relative importance to $\mathrm{Chl}$ movement and thylakoid structural dynamic, which showed changes affected by the light intensity in many dicot species.

\section{References}

Allard G., Nelson C.J., Pallardy S.G.: Shade effects on tall fescue: I. Leaf anatomy and dry matter partitioning. - Crop Sci. 31: 163-167, 1991a.

Allard G., Nelson C.J., Pallardy S.G.: Shade effects on growth of tall fescue: II. Leaf gas exchange characteristics. - Crop Sci. 31: 167-172, 1991b.

Anderson J.M., Goodchild D.J., Boardman N.K.: Composition of the photosystems and chloroplast structure in extreme shade plants. - BBA-Bioenergetics 325: 573-585, 1973.

Anderson J.M., Horton P., Kim E.-H., Chow W.S.: Towards elucidation of dynamic structural changes of plant thylakoid architecture. - Philos. T. Roy. Soc. B 367: 3515-3524, 2012.

Awada T., Perry M.E.L., Schacht W.H.: Photosynthetic and growth responses of the $\mathrm{C}_{3}$ Bromus intermis and the $\mathrm{C}_{4}$ Andropogon gerardii to tree canopy cover. - Can. J. Plant Sci. 
83: 533-540, 2003.

Beard J.B.: Shade stresses and adaptation mechanisms of turfgrasses. - Int. Turfgrass Soc. Res. J. 8: 1186-1195, 1997.

Behera R.K., Choudhury N.K.: Photosynthetic characteristics of chloroplasts of primary wheat leaves grown under different irradiance. - Photosynthetica 39: 11-15, 2001.

Bell G.E., Danneberger T.K., McMahon M.J.: Spectral irradiance available for turfgrass growth in sun and shade. - Crop Sci. 40: 189-195, 2000.

Boardman N.K.: Comparative photosynthesis of sun and shade plants. - Ann. Rev. Plant Physio. 28: 355-377, 1977.

Carter G.A.: Ratios of reflectances in narrow wavebands as indicators of plant stress. - Int. J. Remote Sens. 15: 697-703, 1994.

Causin H.F., Jauregui R.N., Barneix A.J.: The effect of light spectral quality on leaf senescence and oxidative stress in wheat. - Plant Sci. 171: 24-33, 2006.

Cayssials V., Rodríguez C.: Functional traits of grasses growing in open and shaded habitats. - Evol. Ecol. 27: 393-407, 2013.

Chhetri M., Fontanier C., Koh K. et al.: Turf performance of seeded and clonal bermudagrasses under varying light environments. - Urban For. Urban Gree. 43: 126355, 2019.

De La Mata L., Cabello P., De La Haba P., Agüera E.: Study of the senescence process in primary leaves of sunflower (Helianthus annuus L.) plants under two different light intensities. - Photosynthetica 51: 85-94, 2013.

Estrada F., Escobar A., Romero-Bravo S. et al.: Fluorescence phenotyping in blueberry breeding for genotype selection under drought conditions, with or without heat stress. - Sci. Hortic.-Amsterdam 181: 147-161, 2015.

Gao Y., Li D.: Detecting salinity stress in tall fescue based on single leaf spectrum. - Sci. Hortic.-Amsterdam 138: 159-164, 2012.

Gardner D.S., Taylor J.A.: Change over time in quality and cover of various turfgrass species and cultivars maintained in shade.HortTechnology 12: 465-469, 2002.

Gilbert W.B., DiPaola J.M.: Cool season turfgrass cultivars performance in the shade. - In: Lemaire F. (ed.): Proceedings of the Fifth International Turfgrass Research Conference, Avigon (France), 1985.

Gregoriou K., Pontikis K., Vemmos S.: Effects of reduced irradiance on leaf morphology, photosynthetic capacity, and fruit yield in olive (Olea europaea L.). - Photosynthetica 45: 172-181, 2007.

Guenni O., Romero E., Guédez Y. et al.: Influence of low light intensity on growth and biomass allocation, leaf photosynthesis and canopy radiation interception and use in two forage species of Centrosema (DC.) Benth. - Grass Forage Sci. 73: 967-978, 2018.

Heath R.L., Packer L.: Photoperoxidation in isolated chloroplasts: I. Kinetics and stoichiometry of fatty acid peroxidation. Arch. Biochem. Biophys. 125: 189-198, 1968

Hodges D.M., DeLong J.M., Forney C.F., Prange K.R.: Improving the thiobarbituric acid-reactive-substances assay for estimating lipid peroxidation in plant tissues containing anthocyanin and other interfering compounds. - Planta 207: 604-611, 1999.

Hothem S.D., Marley K.A., Larson R.A.: Photochemistry in Hoagland's nutrient solution. - J. Plant Nutr. 26: 845-854, 2003.

Hunter A., Shorten R., McDonagh D.: The effect of supplementary and replacement lighting on turfgrass growth and development. - Int. Turfgrass Soc. Res. J. 11: 807-816, 2009.

Jiang Y., Carrow R.N., Duncan R.R.: Physiological acclimation of seashore paspalum and bermudagrass to low light. - Sci. Hortic.-Amsterdam 105: 101-115, 2005.
Kephart K.D., Buxton D.R.: Forage quality responses of $\mathrm{C}_{3}$ and $\mathrm{C}_{4}$ perennial grasses to shade. - Crop Sci. 33: 831-837, 1993.

Kihara M., Ushijima T., Yamagata Y. et al.: Light-induced chloroplast movements in Oryza species. - J. Plant Res. 133: 525-535, 2020.

Kubásek J., Urban O., Šantrůček J.: $C_{4}$ plants use fluctuating light less efficiently than do $\mathrm{C}_{3}$ plants: a study of growth, photosynthesis and carbon isotope discrimination. - Physiol. Plantarum 149: 528-539, 2013.

Lichtenthaler H.K.: Chlorophyll and carotenoids: pigments of photosynthetic biomembranes. - Method. Enzymol. 148: 350$382,1987$.

Lichtenthaler H.K., Babani F., Navrátil M., Buschmann C.: Chlorophyll fluorescence kinetics, photosynthetic activity, and pigment composition of blue-shade and half-shade leaves as compared to sun and shade leaves of different trees. Photosynth. Res. 117: 355-366, 2013.

Mathur S., Jain L., Jajoo A.: Photosynthetic efficiency in sun and shade plants. - Photosynthetica 56: 354-365, 2018.

Matsubara T., Kosugi Y., Takanashi S., Otsuka K.: Gas exchange and growth/decline model of $\mathrm{C}_{3}$ turfgrass fields under various light conditions. - Ecol. Model. 397: 107-121, 2019

Missihoun T.D., Kotchoni S.O., Bartels D.: Aldehyde dehydrogenases function in the homeostasis of pyridine nucleotides in Arabidopsis thaliana. - Sci. Rep.-UK 8: 2936, 2018.

Murchie E.H., Horton P.: Acclimation of photosynthesis to irradiance and spectral quality in British plant species: chlorophyll content, photosynthetic capacity and habitat preference. - Plant Cell Environ. 20: 438-448, 1997.

Pandey S., Kushwaha R.: Leaf anatomy and photosynthetic acclimation in Valeriana jatamansi L. grown under high and low irradiance. - Photosynthetica 43: 85-90, 2005.

Petrova N., Paunov M., Stoichev S. et al.: Thylakoid membrane reorganization, induced by growth light intensity, affects the plants susceptibility to drought stress. - Photosynthetica 58: 369-378, 2020.

Poór P., Borbély P., Bódi N. et al.: Effects of salicylic acid on photosynthetic activity and chloroplast morphology under light and prolonged darkness. - Photosynthetica 57: 367-376, 2019.

Poulson M.E., Thai T.: Effect of high light intensity on photoinhibition, oxyradicals and artemisinin content in Artemisia annua L. - Photosynthetica 53: 403-409, 2015.

Prioul J.-L., Brangeon J., Reyss A.: Interaction between external and internal conditions in the development of photosynthetic features in a grass leaf. I. Regional responses along a leaf during and after low-light or high-light acclimation. - Plant Physiol. 66: 762-769, 1980.

Roeber V.M., Bajaj I., Rohde M. et al.: Light acts as a stressor and influences abiotic and biotic stress responses in plants. Plant Cell Environ. 44: 645-664, 2021.

Sagun J.V., Badger M.R., Chow W.S., Ghannoum O.: Cyclic electron flow and light partitioning between the two photosystems in leaves of plants with different functional types. - Photosynth. Res. 142: 321-334, 2019.

Schwartz B., Zhang J., Fox J., Peake J.: Turf performance of shaded 'TifGrand' and 'TifSport' hybrid bermudagrass as affected by mowing height and trinexapac-ethyl. HortTechnology 30: 391-397, 2020.

Sims D.A., Gamon J.A.: Relationships between leaf pigment content and spectral reflectance across a wide range of species, leaf structures, and developmental stages. - Remote Sens. Environ. 81: 337-354, 2002.

Uzunova A.N., Popova L.P.: Effects of salicylic acid on leaf anatomy and chloroplast ultrastructure of barley plants. - 
Photosynthetica 38: 243-250, 2000.

Van Huylenbroeck J.M., Lootents P., Van Bockstaele E.: Photosynthetic characteristics of perennial ryegrass and red fescue turf-grass cultivars. - Grass Forage Sci. 54: 267-274, 1999.

Van Huylenbroeck J.M., Van Bockstaele E.: Effects of shading on photosynthetic capacity and growth of turfgrass species. Int. Turfgrass Soc. Res. J. 9: 353-359, 2001.

Woledge J.: The effect of light intensity during growth on the subsequent rate of photosynthesis of leaves of tall fescue
(Festuca arundinacea Schreb.). - Ann. Bot.-London 35: 311 322, 1971.

Yamazaki J., Shinomiya Y.: Effect of partial shading on the photosynthetic apparatus and photosystem stoichiometry in sunflower leaves. - Photosynthetica 51: 3-12, 2013.

Zhang L.X., Guo Q.S., Chang Q.S. et al.: Chloroplast ultrastructure, photosynthesis and accumulation of secondary metabolites in Glechoma longituba in response to irradiance.Photosynthetica 53: 144-153, 2015.

(C) The authors. This is an open access article distributed under the terms of the Creative Commons BY-NC-ND Licence. 